\title{
Review Article \\ Review of Adaptive Cell Selection Techniques in LTE-Advanced Heterogeneous Networks
}

\author{
M. A. Gadam, ${ }^{1}$ Maryam Abdulazeez Ahmed, ${ }^{1}$ Chee Kyun Ng, ${ }^{1,2}$ \\ Nor Kamariah Nordin, ${ }^{1}$ Aduwati Sali, ${ }^{1}$ and Fazirulhisyam Hashim ${ }^{1}$ \\ ${ }^{1}$ Department of Computer and Communication Systems Engineering, Universiti Putra Malaysia (UPM), \\ 43400 Serdang, Selangor, Malaysia \\ ${ }^{2}$ Malaysian Research Institute on Ageing, Universiti Putra Malaysia (UPM), 43400 Serdang, Selangor, Malaysia
}

Correspondence should be addressed to M. A. Gadam; agmohammed@fptb.edu.ng

Received 19 November 2015; Revised 14 March 2016; Accepted 17 March 2016

Academic Editor: Khoa Le

Copyright (C) 2016 M. A. Gadam et al. This is an open access article distributed under the Creative Commons Attribution License, which permits unrestricted use, distribution, and reproduction in any medium, provided the original work is properly cited.

\begin{abstract}
Poor cell selection is the main challenge in Picocell (PeNB) deployment in Long Term Evolution- (LTE-) Advanced heterogeneous networks (HetNets) because it results in load imbalance and intercell interference. A selection technique based on cell range extension (CRE) has been proposed for LTE-Advanced HetNets to extend the coverage of PeNBs for load balancing. However, poor CRE bias setting in cell selection inhibits the attainment of desired cell splitting gains. By contrast, a cell selection technique based on adaptive bias is a more effective solution to traffic load balancing in terms of increasing data rate compared with static biasbased approaches. This paper reviews the use of adaptive cell selection in LTE-Advanced HetNets by highlighting the importance of cell load estimation. The general performances of different techniques for adaptive CRE-based cell selection are compared. Results reveal that the adaptive CRE bias of the resource block utilization ratio (RBUR) technique exhibits the highest cell-edge throughput. Moreover, more accurate cell load estimation is obtained in the extended RBUR adaptive CRE bias technique through constant bit rate (CBR) traffic, which further improved load balancing as against the estimation based on the number of user equipment (UE). Finally, this paper presents suggestions for future research directions.
\end{abstract}

\section{Introduction}

The Long Term Evolution (LTE) air interface technology was introduced worldwide by the Third-Generation Partnership Project (3GPP); this technology is an improved third-generation (3G) mobile communication system with increased system capacity. However, macrobase station deployment of conventional $3 \mathrm{G}$ cellular systems cannot cope with the mobile data traffic demand. Further research in the 3GPP has evolved with Release 10 version, also known as LTEAdvanced [1], to surpass performance requirements for the International Mobile Telecommunication-Advanced (IMTA) and provide optimal solutions with low latency as well as improved cell coverage, cell-edge throughput, and overall system capacity [2].

LTE-Advanced basic techniques have reached the theoretical Shannon capacity limit and thus cannot provide any significant capacity improvement. These techniques function under low signal-to-interference-to-noise ratios (SINR) because of low signal power received as a result of signal attenuation. The increasing demand for data services can be satisfied by deploying additional macrobase stations, also known as evolved node B (eNB); however, this technique is difficult and expensive in 3GPP. Thus, deployment of the heterogeneous network (HetNet) $[3,4]$ has been explored to significantly improve the network capacity. Low-power nodes in HetNets, such as Picocells or Pico-eNBs, (PeNBs), are overlaid on the Macro-eNB (MeNB) coverage area; these nodes coexist and share the same spectrum to achieve the desired cell splitting gain [5].

The performance gain of HetNet is achieved by offloading MeNBs to PeNBs. This goal can be accomplished by improving indoor coverage and cell-edge user throughput and increasing the spectral efficiency per unit area. HetNet is 
a network that consists of various wireless access technologies and utilizes a different style of deployment planning from that of a homogeneous network [11]. HetNet is characterized according to its transmission power, antenna height, access mode, and backhaul connection to other cells. Despite its varied capabilities, constraints, and operating functionalities, HetNet can improve the network capacity per unit area through spatial reuse of the spectra. Moreover, the use of this network reduces energy consumption and is a costeffective means of coverage extension with minimal or no upfront planning $[3,12,13]$. Hence, HetNet is a potential major capacity enhancer of LTE-Advanced.

The benefits of HetNets, especially PeNBs, in offloading traffic from MeNBs cannot be sufficiently exploited if an appropriate cell selection technique [12] is not used in the system design. In cell selection, user equipment (UE) is attached to either PeNB or MeNB by using the received signal strength to be assigned to resources and/or for traffic offloading. Traffic load balancing and throughput maximization are important objectives of cell selection. UE throughput is measured using the available resources allocated $[14,15]$ and the channel quality of the UE. An inverse proportion exists between the allocated resources per UE and the number of pieces of UE attached to a given MeNB or PeNB. In a homogeneous network, cell selection is easy because of similar transmission power of all MeNBs. Thus, the UE connects to the MeNB with the highest reference signal received power (RSRP). Assuming a uniform UE distribution within a coverage area, cell selection can achieve load balancing. However, in a HetNet with different transmission power levels, simple reference signal received power (RSRP) cannot achieve load balance as evident in the homogeneous case. The higher transmission power of the MeNBs than that of PeNBs results in wider coverage area. Hence, the UE is more associated with the MeNBs than with the PeNBs and may induce traffic load imbalance.

Cell selection based on cell range extension (CRE) bias is introduced to LTE-Advanced HetNet to mitigate traffic load imbalance during PeNB-MeNB deployment [16]. This technique successfully increases PeNB utilization by offloading UE to the PeNBs. However, CRE bias values must be carefully selected because of the dynamic nature of traffic distribution and service demand to avoid poor bias setting [17]. Thus, a cell selection technique that adapts to UE distribution and load conditions in HetNet is introduced for load balancing in accordance with the methods for dynamic deployment of PeNBs-MeNBs. Several algorithms of this cell selection technique have been studied [6-10]. $\mathrm{Gu}$ et al. [6] proposed a practical adaptation algorithm with resource block utilization ratio (RBUR) as a metric to estimate load condition in a system. Subsequently, Gu et al. [7] improved RBUR and proposed RBUR extension (RBUR ext); in RBUR ext, constant bit rate (CBR) traffic was adopted to estimate load condition in a system. Moreover, a simple decentralized adaptive cell association (SDACA) algorithm was developed using a combination of resource and MeNB indices to estimate load condition [9]. Q-learning-based adaptive cell selection using a set of resource blocks (RBs) and UE distribution was also proposed to represent load condition in a system [8]. Furthermore, cell selection based on adaptive control CRE (ACCRE) was presented to estimate load condition for adaptive cell selection; this algorithm was based on the SINR of UE and the ratio of the number of pieces of UE connected to PeNBs and MeNBs [10].

This paper provides a review of adaptive cell selection techniques in LTE-Advanced to attain improved balanced traffic and system capacity. Adaptive bias-based cell selection methods exhibit higher performance than that of static bias methods. Methods of load estimation, as metric for adaptive cell selection, are also compared. Moreover, load estimation is compared among adaptive cell selection methods as a metric for system performance. Adaptive cell selection based on the RBUR ext exhibits the optimal performance in load estimation using CBR traffic compared with estimation using the number of pieces of UE in other cell selection algorithms.

The remaining portion of this paper is structured as follows. Section 2 presents the overview of the LTE-Advanced in HetNets. Section 3 provides a discussion of issues in MeNB-PeNB deployment. Section 4 enumerates the cell selection process. Section 5 displays the results of different examined adaptive cell selection techniques with related load conditions to determine the effect of unbalanced load. Section 6 shows a comparison of adaptive cell selection techniques under different load conditions. Finally, Section 7 imparts the conclusion of the study and suggestions for future work.

\section{Overview of LTE-Advanced in HetNets}

The International Telecommunications Union (ITU) has set requirements for IMT-A radio access technology to improve its performance compared with the evolved IMT-2000. ITU aims to satisfy the ever-increasing demand for high data rates caused by proliferation of mobile devices. The key considerations of the IMT-A include the following: wide transmission bandwidth of up to $40 \mathrm{MHz}$ and possible extension to $100 \mathrm{MHz}$; increased peak spectral efficiency up to about $30 \mathrm{bps} / \mathrm{Hz}$ in downlink and $15 \mathrm{bps} / \mathrm{Hz}$ in uplink; reduced latency to less than $10 \mathrm{~ms}$ in UE; increased data rates up to $1 \mathrm{Gbps}$ in downlink and $500 \mathrm{Mbps}$ in uplink; increased cell-edge user efficiency up to $0.075 \mathrm{bps} / \mathrm{Hz}$ in downlink and $0.05 \mathrm{bps} / \mathrm{Hz}$ in uplink; and other considerations related to deployment flexibility and cost-effectiveness of the overall system. Radio access technologies that satisfy the IMTA requirements are also known as fourth-generation (4G) wireless access technologies, which are currently deployed by some mobile service providers [18].

The 3GPP adopted LTE Release 8/9 (LTE Rel. 8/9) as the baseline for enhancement to comply with the IMT-A requirements. Enhanced LTE Rel. 8/9 was submitted as a proposal for IMT-A and then approved by the ITU as a qualified IMT-A radio access technology, known as LTEAdvanced (LTE-A Rel. 10/11). The new enhanced features of LTE-A Rel. 10/11 that exceed the ITU requirements include the following: carrier aggregation (CA), advanced multiple input multiple output (MIMO) techniques, coordinated multipoint transmission/reception (COMP), relaying, and support for multitier deployment [5], also known as HetNet. 


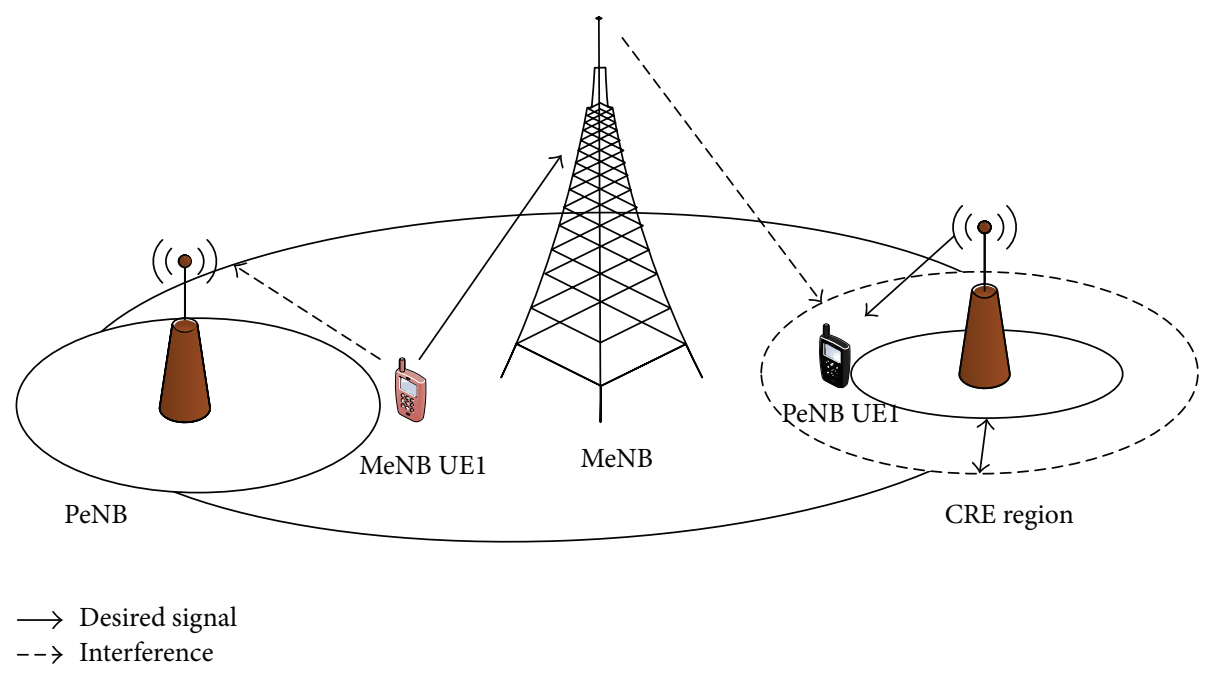

Figure 1: MeNB-PeNB deployment scenario [3].

The forecasted high data traffic explosion has prompted LTE-Advanced to improve network capacity by increasing node densification [19]. However, intercell interference and capital expenditure cost associated with high-power node deployment render this approach as not feasible. These challenges are addressed by using low-power node technology. Low-power nodes are classified as PeNBs, Femtos, and relays on the basis of their access configuration, transmit power, or deployment method $[3,13]$. A network with a mixed composition of macrobase station and low-power nodes, mixed access modes, and backhaul is referred to as HetNet.

PeNBs are an important component for improving the overall system capacity when deployed in a local region with high data traffic. PeNBs refer to low-power nodes deployed by the operator with backhaul and access features similar to those of MeNBs (Figure 1). These nodes are normally deployed in a hotspot area to serve UE within the range of $300 \mathrm{~m}$ and hold a typical transmission power between 23 and $30 \mathrm{dBm}$ [20]. PeNBs are mainly deployed to improve the capacity, extend services to indoor or outdoor environments with coverage holes, and operate in open access mode. Thus, any user within the network range can automatically connect to PeNBs. However, the cell splitting gain of a PeNB is limited by its small transmission power, which allows several pieces of UE to connect to MeNBs. CRE [21] influences the offloading of additional traffic to PeNBs for load balancing and increasing throughput. A positive bias value, called CRE bias, is added to the RSRP of the UE to extend the coverage of PeNB transmission within the MeNB (Figure 1). CRE bias influences the UE to connect to PeNBs as their serving cell in a maximum (RSRP + CRE bias) cell selection criterion [22], thereby increasing the offloading gain. CRE bias is set by compensating the differences between the transmission power of MeNBs and PeNBs. The CRE bias setting can be based on UE distribution and traffic models [13]. However, CRE is limited by the effect of interference from MeNBs, especially cell-edge UE $[23,24]$.

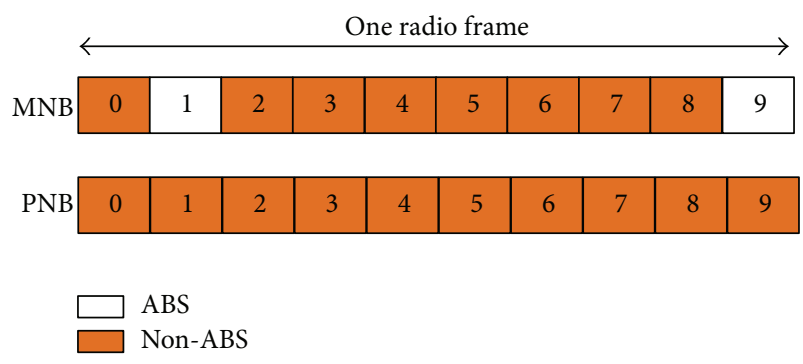

Figure 2: Example of ABS for eICIC [3].

The cell splitting gain of the HetNets can be achieved when the effects of intercell interference by aggressor cells on the victim UE are mitigated. For instance, MeNBs severely interfere with PeNB cell-edge UE in a MeNBPeNB CRE scenario. As such, enhanced intercell interference coordination (eICIC) is employed to mitigate the effect of interference by the MeNB. The eICIC $[3,25]$ concept is a custom-planned technique used to alleviate the potential downlink interference that may arise in multilayer networks because of cochannel deployment of MeNBs and PeNBs. In contrast to LTE Rel. 8, which mitigates interference based on data signals, LTE Rel. 10 access scheme offers protection for physical data and control channels by using eICIC. The eICIC concept refers to the muting of certain subframes of some MeNBs to reduce interference to other cells (Figure 2) [3]. The muted subframes are called almost-blank subframes (ABS). The LTE normal subframes carry both data and control signals, whereas ABS resources are characterized by minimum transmission required for backward compatibility with legacy LTE operation, such as the Common Reference Signals (CRS) [26], as well as other mandatory system information. The orientation and number of CRS depend on the type of ABS used. For instance, the Multimedia Broadcast Multicast Service Single-Frequency Network (MBSFN) type ABS is used for Multimedia Broadcast Multicast Service (MBMS) in LTE. The MBSFN ABS does not contain CRS 


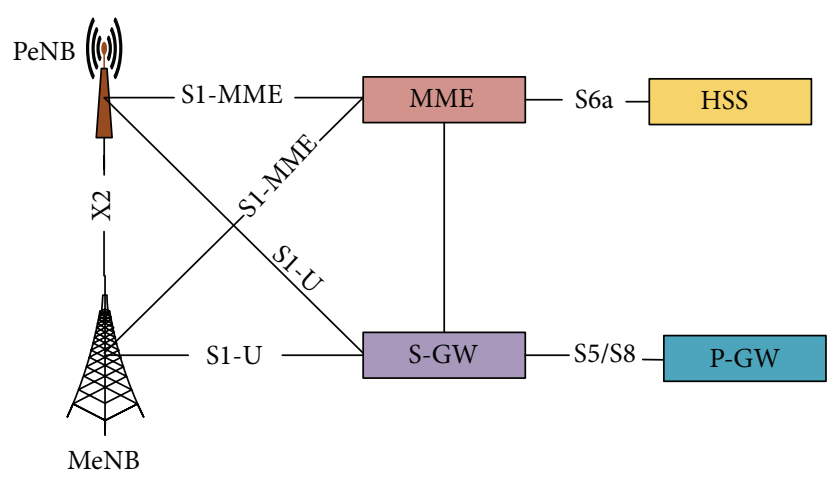

Figure 3: Deployment of the MeNB-PeNB architecture [3].

in the Physical Downlink Shared Data transmission Channel (PDSCH), where data traffic is transmitted. Moreover, nonMBSFN is built from normal subframes and contains CRS in PDSCH $[27,28]$. The challenge in using CRE with eICIC is the optimal selection of the muting ratio with the associated CRE bias value to increase cell-edge UE throughput, average UE throughput, and system area throughput.

\section{PeNB-MeNB Deployment Challenges}

PeNBs are deployed by the operator in the MeNB-PeNB architecture (Figure 3). The PeNBs are placed in the MeNB cell-edge or in a hotspot area to improve UE throughput. The PeNBs hold the same functionalities and protocol stacks as the MeNBs but transmit with lower power [3]. Both MeNBs and PeNBs are connected to the Mobility Management Entity (MME) and Serving Gateway (S-GW) through the S1 interface. The X2-based interface backhaul connects PeNB and MeNB as well as the neighboring MeNBs and PeNBs [2]. Therefore, this deployment supports both S1- and X2-based UE handovers, where X2 interfaces facilitate interference coordination between the MeNB and PeNB. The difference in transmission power and control signals between MeNB and PeNB poses numerous deployment challenges in load balancing and interference management.

The coverage area is not affected by load imbalance in the uplink because the UE possesses equal transmit power. In the downlink, the cell that maximizes RSRP is selected as the serving cell. The MeNB or PeNB that provides the highest uplink coverage for UE may not be the best in the downlink, and the UE cannot select different nodes for the uplink and downlink. Thus, the problem of selecting the best cell as serving cell by the UE is imperative $[29,30]$. The UE measures and selects the cell with the highest RSRP in the downlink as its serving cell. Thus, PeNBs will serve a smaller number of pieces of UE compared with MeNBs because of the small transmission power of the former. This phenomenon causes load imbalance because the PeNBs will be underutilized and the MeNBs will be overloaded. Therefore, CRE is employed to correct load imbalance in the downlink. However, the primary challenge of using CRE in the downlink is the resulting poor setting of the bias value, which results in low offloading gain because of the small coverage area of PeNB and severe interference from MeNB, especially to the PeNB cell-edge UE.

The conventional static bias setting provides a fixed CRE bias to all UE from the donor MeNB. Basically, the high CRE bias value implies higher uploading of UE to the PeNB, whereas the low CRE bias value uploads a small number of pieces of UE to the PeNBs. Nevertheless, some issues persist in the static CRE bias setting from the overall system perspective. The low bias values result in unfavorable system performance when only minimal UE is offloaded to the PeNBs because of the small coverage area; thus, the resource usage opportunity in the PeNBs is not adequately exploited. The PeNB coverage area is enlarged with a large bias value, which leads to high number of users being accommodated. However, the PeNBs experience scheduling outage because of the large distance of some pieces of UE from PeNBs and the poor RSRP. Moreover, the UE close to MeNBs experiences severe interference [29]. The offloaded UE cannot achieve the desired data rate if resources for scheduling are insufficient; therefore, resource availability is an important factor that should be considered in designing cell selection algorithms $[31,32]$. Furthermore, bias values in PeNBs must be optimally designed to achieve the optimal system performance.

\section{Cell Selection}

Cell selection is a process in which pieces of UE attach themselves to the serving cell for communication under certain criteria. In conventional cell selection, the UE choice of serving cell is determined by the highest received power called the RSRP. The MME in Figure 3 [3] is the main entity in the control plane responsible for the signaling between the UE and core network. The radio resource control (RRC) layer controls the information required by UE to access the first point of entry to the network. The UE at any given time is in either one of two RRC states: RRC_IDLE or RRC_CONNECTED.

In the RRC_IDLE state, the UE initiates an RRC connection which MeNB adopts for communication. This process is known as cell selection, which is followed by processes of initial cell detection, received signal strength measurement, reading of system data, and final association. In the RRC_CONNECTED state, this process is initiated and managed by the network and is known as handover. The handover in the RRC_CONNECTED state depends on the link quality and other parameters [33]. The architecture of the MeNB-PeNB deployment supports both S1 and X2 UE based handovers as depicted in Figure 3. X2 interface acts as a backhaul that connects the MeNB and PeNB and also enables interference coordination between the two. However, given the difference in the power of transmission in the MeNB-PeNB scenario, a little enhancement in the handover process is needed to offload more data traffic to PeNB. Hence, cell selection in MeNB-PeNB scenario employed X2-based handover with CRE bias technique embedded by the MeNB as part of the handover decision in RRC_CONNECTED state [34]. 


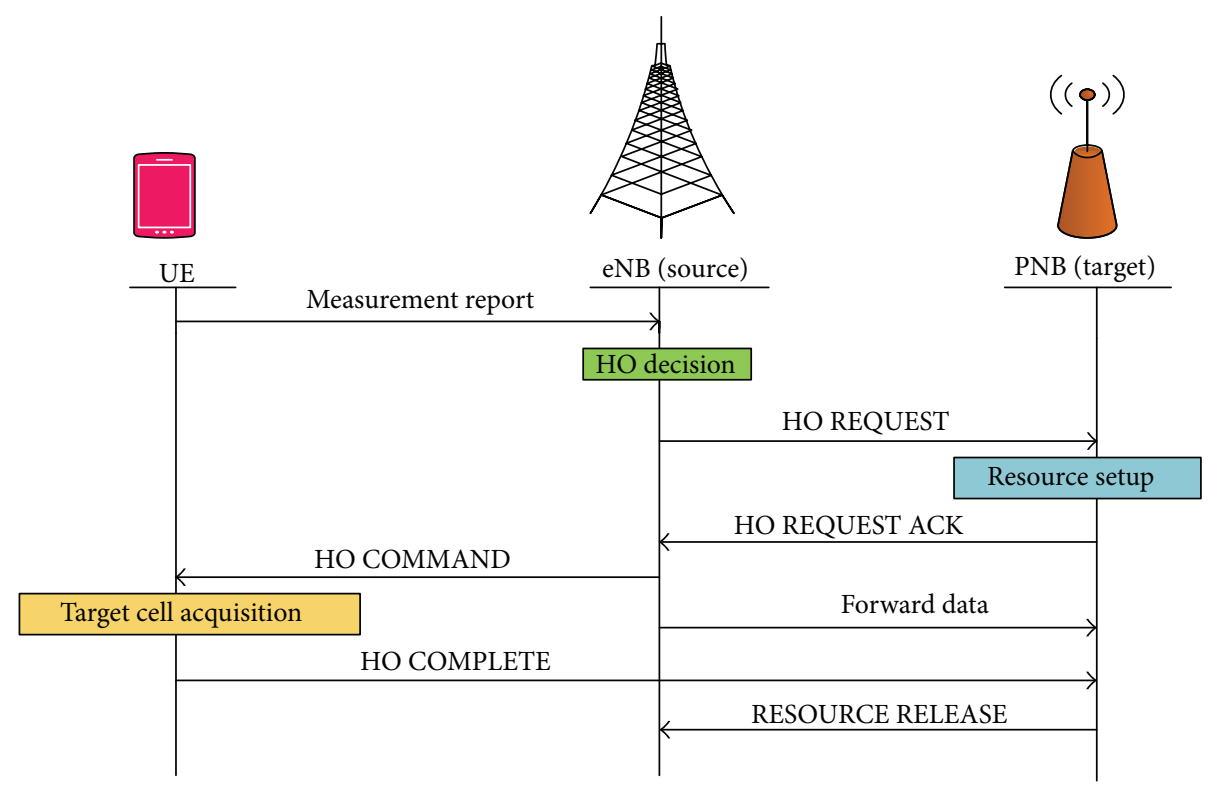

FIGURE 4: X-2-based handover procedure [3].

The MeNB-PeNB X2-based handover procedure is illustrated in Figure 4. The RSRP of neighboring MeNBs and PeNBs is measured by the UE and reported to its serving MeNB periodically. The handover $(\mathrm{HO})$ decision $[13,35]$ is based on the RSRP measurement report. If PeNB holds the highest RSRP, the handover request (HO REQUEST) message will be initiated by MeNB and forwarded via the X2 interface. The PeNB will respond with a handover acknowledgment (HO ACK) message after receiving the HO REQUEST message and preparing radio resources for the UE. The MeNB will then initiate the acquisition process of the PeNB by sending an HO COMMAND to the UE. The MeNB will then initiate data forwarding to the PeNB to prevent any data loss. The UE informs the PeNB of the completion of cell acquisition process with an HO COMPLETE message. After receiving the $\mathrm{HO}$ COMPLETE message, the PeNB sends a RESOURCE RELEASE message to the MeNB via the X2 interface, signifying the completion of the whole handover process. The goal of the CRE bias embedding by the MeNB as part of the handover process in a MeNB-PeNB scenario is to increase the PeNB coverage such that more $\mathrm{UE}$ is handed over to the MeNB. Given the relatively small power of transmission of the PeNB, the CRE bias is added to the RSRP of the PeNB before comparing with the RSRP of the $\mathrm{MeNB}$ [36]. Hence, the MeNB can hand over UE even with a relatively smaller RSRP value to the PeNB. Consequently, this occurrence would increase the system cell splitting gain and the offloading of UE to the PeNB.

\section{Adaptive Cell Selection}

In this section, adaptive cell selection techniques are discussed with associated load conditions. The number of pieces of UE in the cell may not be accurately known in reality to represent the traffic load conditions in a cell. This shortcoming may result in a wrong bias value setting. Different techniques are presented to represent the load conditions that adaptively decide the bias values to be assigned for optimal throughput performance. The metrics considered are offloading gain, cell-edge, and average UE throughputs, respectively.

5.1. Adaptive Cell Range Control with RBUR. The authors in [6] proposed an adaptive cell range control algorithm based on RBUR. It more accurately estimates the varying load condition in each cell than other algorithms to avoid severe interference to cell-edge UE. As such, the proposed algorithm achieves throughput maximization and traffic load balancing in the system. The algorithm dynamically increases the coverage area of PeNBs using the RBUR to avoid the unnecessary severe interference associated with the CRE. Cell-specific offset (CSO), another name of CRE bias, adjusts the coverage area of PeNBs based on this metric. A threshold value of RBUR and the initial value of CSO are set, and a new attempted value of CSO is calculated. A RBUR greater than the threshold suggests that the MeNB is overloaded, and the $\mathrm{CSO}$ will be increased to offload traffic to PeNB. The increase in the CSO value is directly proportional to the cell load.

System throughput depends on channel quality and availability of resources for UE scheduling. Thus, regardless of channel quality in a high traffic network, the throughput is determined jointly with the available resources. The throughput of a given cell is limited by the channel quality and available resources for low and high traffic, respectively. Figure 5 compares the cell-edge UE throughput of MeNB with and without PeNBs at a fixed CSO under different traffic situations. The cell-edge UE throughput in a hotspot area is degraded at low traffic volume because of impairment in the SINR when the PeNB is added. However, the cell-edge UE throughput increases in high traffic volume because of the availability of sufficient resources to schedule addition of UE. 


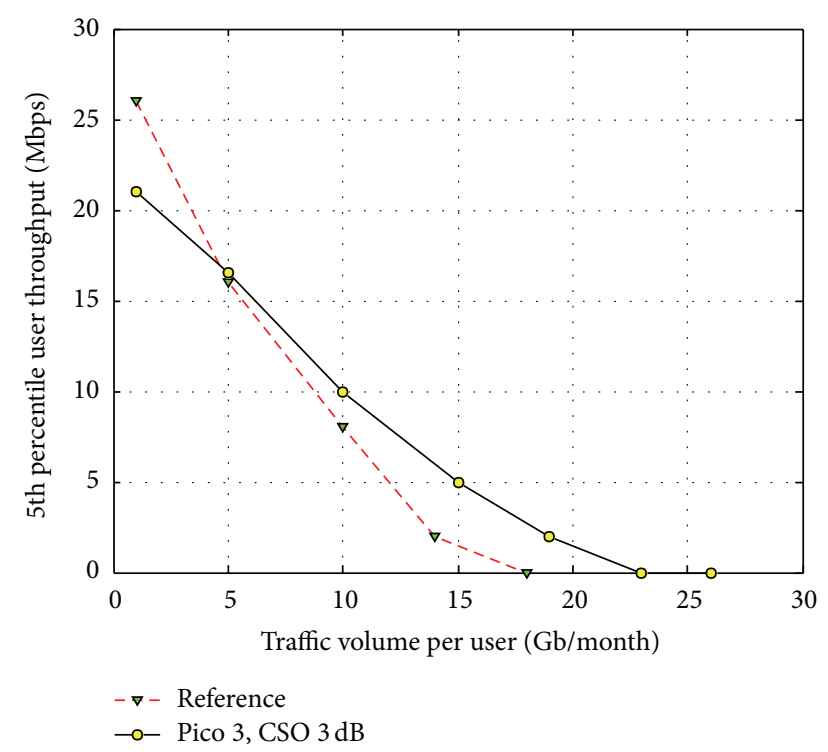

FIgUre 5: Cell-edge UE throughput with and without PeNB [6].

Given the varying traffic situation in a real network, a fixed CSO cannot guarantee the optimal throughput performance. Therefore, adaptive CSO that extends the PeNB coverage based on the traffic situation can optimally improve the cell-edge UE throughput. The RBUR CSO will be updated adaptively to produce a new CSO value that can optimally improve the cell-edge UE throughput using RBUR metric to represent the cell load. The RBUR is low when the throughput of UE is limited by its SINR, and thus, low CSO is selected to avoid increasing the number of pieces of UE in the cell-edge. Conversely, a high RBUR implies that the MeNB is resource limited, and high CSO is selected to offload more pieces of UE to the PeNBs with more available resources. Therefore, the CSO level can be varied depending on the load condition in the cell.

5.2. Capacity Analysis and Optimization with Adaptive Cell Range Control Using RBUR. The authors in [7] proposed an adaptive extension of a PeNB coverage area by adding a CSO during cell selection. This extension of adaptive RBUR-based $\mathrm{CSO}$ produces a new CSO value that can optimally improve the overall capacity using RBUR metrics to represent the cell load. The RBUR, in this case, considers a typical traffic called CBR services against the number of UE RBUR-based traffic types in [6]. The RBUR threshold is set for comparison; in this case, the UE in the cell is considered to be resource limited, when the RBUR is larger than the threshold and SINR limited, when the RBUR is lower than the threshold. This adaptive algorithm adjusts the CSO setting to optimize the overall system capacity. The CSO setting is periodically updated in the algorithm. The current CSO value is updated with a new value instantly, such that the new attempting value will increase overall capacity. The attempting CSO setting is obtained by either increasing or decreasing a step relative to the current CSO. The new CSO that results in the best overall system capacity is then selected. The graph of normalized cell

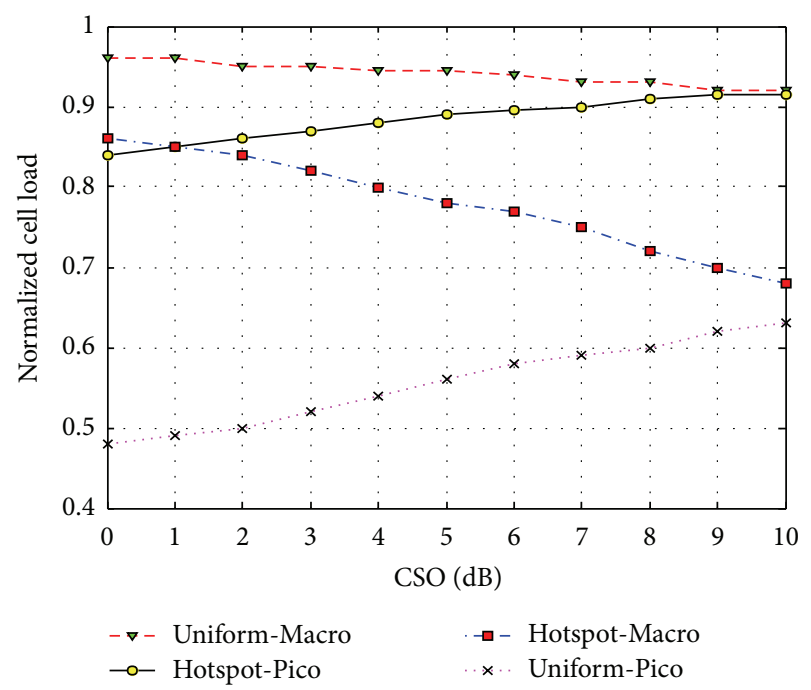

FIgure 6: Cell load with different CSOs [7].

load with the CSO is shown in Figure 6. The cell load increases with the increasing CSO in all the PeNBs and decreases with an increase in CSO in the MeNBs.

The extension of the adaptive RBUR algorithm is simple, and it exhibits a better throughput and offloading performance in the uniform distributed scenario. The extension holds the ability to adaptively select the CSO from RBUR measured directly from the network with no feedback from the UE. The updating algorithm must consider the number of PeNBs, and, therefore, a coordination between MeNBs and PeNBs is necessary for the algorithm.

5.3. Q-Learning-Based Adaptive CRE with RB Rationing. Qlearning, a machine learning (ML) technique that may serve as an alternative to trial-and-error (static) methods of the bias setting in HetNets, is proposed in [8] to optimally determine the bias value. The main feature of Q-learning is the ability to compare an action with previous actions to give the desired or intended output through learning without any reference model of the environment. The ML determines applications in HetNets with different radio accesses but coexist in the same environment, where the parameter adjustment poses a great challenge [37]. Q-learning finds applications in distributed interference management in multicell networks [38], resource allocation capacity self-optimization, and cell selection [39]. In essence, knowledge exchange and intelligent behavior are two main features of Q-learning. However, Q-learning is a learning-based algorithm that involves a repetitive process; hence, memory problems may appear because of long convergence time. The Q-learning flow is illustrated in Figure 7. In the concept of Q-learning-based cell range expansion [8], all pieces of UE act as agents and can independently decide their bias values to minimize outages. Q-learning is also distributed because the UE does not share information unlike the centralized method. The advantage of the distributed Q-learning method in cell selection is that it allows UE to create an independent decision on increasing 


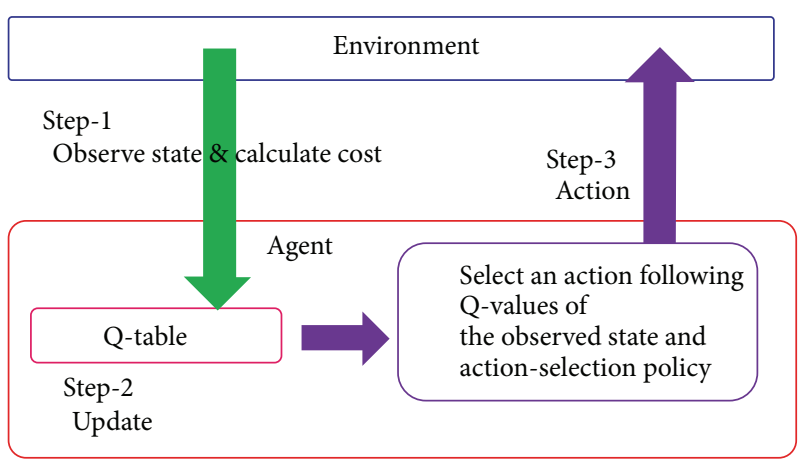

Figure 7: Q-learning flow [8].

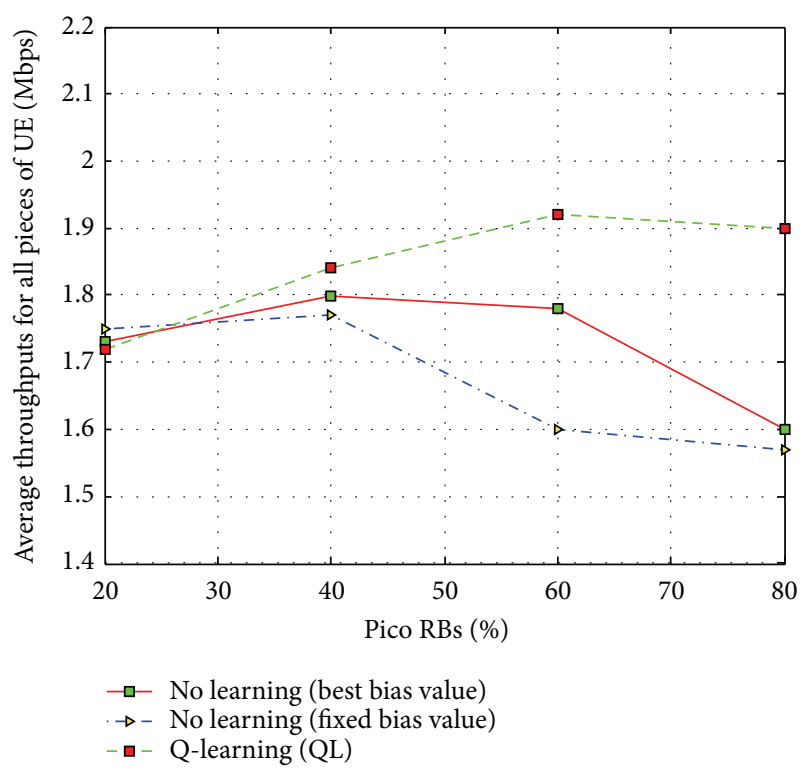

FIgURE 8: Average throughput for all UE [8].

the offloading gain by decreasing loads from the MeNBs to the PeNBs.

The bias values that minimize the number of other UE outages are decided by the UE in accordance with the strongest RSRP from MeNBs or PeNBs with added bias value and also the available RBUR between MeNBs and PeNBs. Each piece of UE makes its decision on selecting optimal bias values depending on the aforementioned situations using Qlearning. Learning is enhanced by increasing the number of stored states in the Q-table, and memory constraint is avoided by the use of a priori data to accelerate the convergence. Figure 8 depicts the performance of the Q-learning approach compared with the common bias approaches in terms of the best and fixed bias values in a system-level simulation. The common bias approaches use the trial-and-error method to search for the bias value that minimizes the number of pieces of UE in an outage. The channel condition is dynamic; hence, the fixed bias approach requires a longer time to converge, and therefore, it is not suitable for the practical environment. The overall system throughput of the Q-learning approach exhibits a better performance when compared with the fixed bias value approach.

The Q-learning of the adaptive CRE bias approach focuses mainly on the machine learning process. The model engages $\mathrm{UE}$ as an agent in multiagent systems that observe its state of the environment from the corresponding sets in the Q-table. The UE learns from the previous performance by analyzing the system parameters. This method is more superior to the cognitive approach because the UE learns from its previous performance before accepting a decision. However, the algorithm in Q-learning will be a complicated architecture in a hotspot area where many PeNBs are deployed for traffic offload. Moreover, the multiagent system can converge only when agents are static and, hence, are not suitable for pieces of UE that are in high speed.

5.4. SDACA. The SDACA method proposed in [9] holds the advantage of fast convergence on the basis of individual UE feedback assisted by a broadcast from respective MeNBs. The method does not require inter-MeNB coordination in cell association decision. The SDACA method is based on the expected throughput measured by each piece of UE when the expected resource bandwidth is broadcasted by the MeNBs. The resources are categorized and indexed as either protected or nonprotected using frequency domain intercell interference coordination (ICIC). A metric based on the combination of MeNB and resource indices, which represent an expected increase in throughput, is used by the UE to determine the cell association. The metric is fed back to MeNBs on each broadcasted resource, and the UE with the highest metric is chosen by the MeNBs before adding to the resource. Each MeNB updates the cell association based on the feedback metric. This method also adapts to the variance in the UE distribution.

The performance of the SDACA method is compared with two CRE-based approaches in a system-level simulation: the CRE-equal bandwidth (CRE-EB), which allocates equal resources to the UE, and the CRE-proportional fair (CRE$\mathrm{PF}$ ), which allocates resources to maximize the geometric mean of UE throughput. Figure 9 depicts the cell-edge UE and average UE throughput as a function of ICIC with the hotspot UE distribution. The SDACA method achieves better cell-edge UE throughput compared with the two CRE-based methods regardless of UE distribution. This result is achieved because the CRE method requires MeNB cooperation in the selection of a common bias to all PeNBs that will maximize the cell-edge UE throughput. Therefore, selecting any bias value may not be optimal.

5.5. Parameter Optimization for Adaptive Control CRE. The authors in [10] proposed an ACCRE that increases the celledge UE throughput and preserves the average UE throughput. The method assumed two different CRE bias values in an easy-to-use approach that results in an optimal CRE bias to each piece of UE. The two CRE bias values are designated as $\mathrm{CRE}_{\text {high }}$ and $\mathrm{CRE}_{\text {low }}$ with wide and small coverage areas, respectively. The cumulative distribution function (CDF) of the SINR measured by all the UE is used to determine 


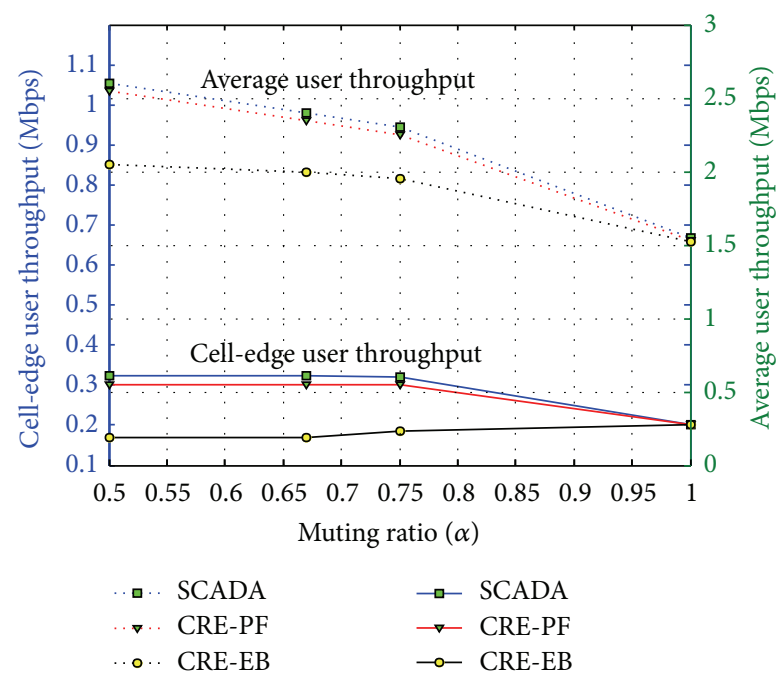

FIGURE 9: Cell-edge and average UE throughputs versus ICIC $(\alpha)$ in hotspot UE distribution [9].

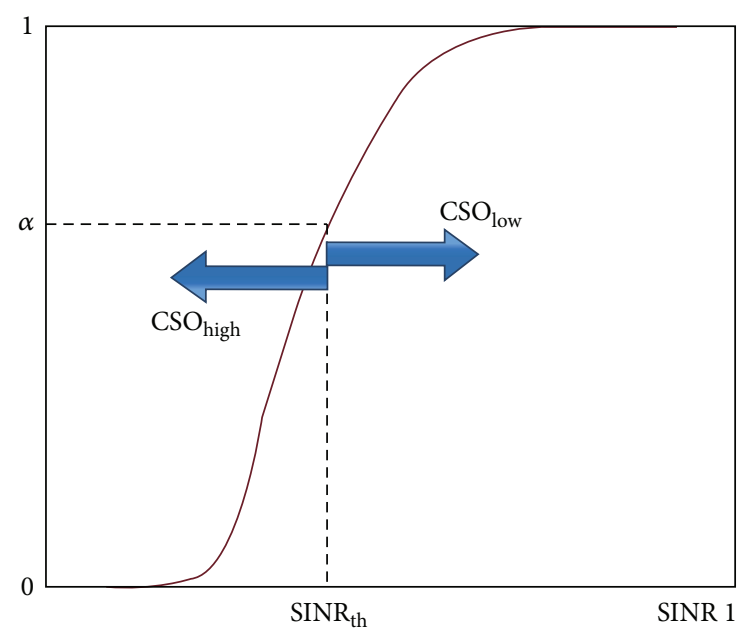

FIGURE 10: CDF of SINR adopted to decide on $\mathrm{CSO}_{\text {high }}$ or $\mathrm{CSO}_{\text {low }}$ $[10]$.

two different CRE biases (Figure 10). The SINR threshold $\left(\mathrm{SINR}_{\mathrm{th}}\right)$ is assumed to satisfy a certain fixed CDF value $\alpha$, and this condition also holds for the relationship between the CRE and SINR. Thus, $\mathrm{CRE}_{\text {low }}$ is applied to UE with SINR greater than $\mathrm{SINR}_{\text {th }}$ and $\mathrm{CRE}_{\text {high }}$ for UE with SINR lower than SINR $_{\text {th }}$. The SINR is measured by the UE from the RSRP of MeNBs. The $\mathrm{CRE}_{\text {low }}$ and $\mathrm{CRE}_{\text {high }}$ settings are based on a previous research on the parameter investigation in [40].

Figure 11 depicts the comparison of the average UE throughput and the cell-edge UE throughput of the ACCRE and the conventional cell selection methods. The average UE throughput decreases with increasing CRE bias (CSO) for the conventional cell selection methods. ACCRE-based cell selection is simple; it increases the cell-edge UE throughput while maintaining the average UE throughput. The algorithm is clarified relative to the conventional (static) CRE-based cell selection.

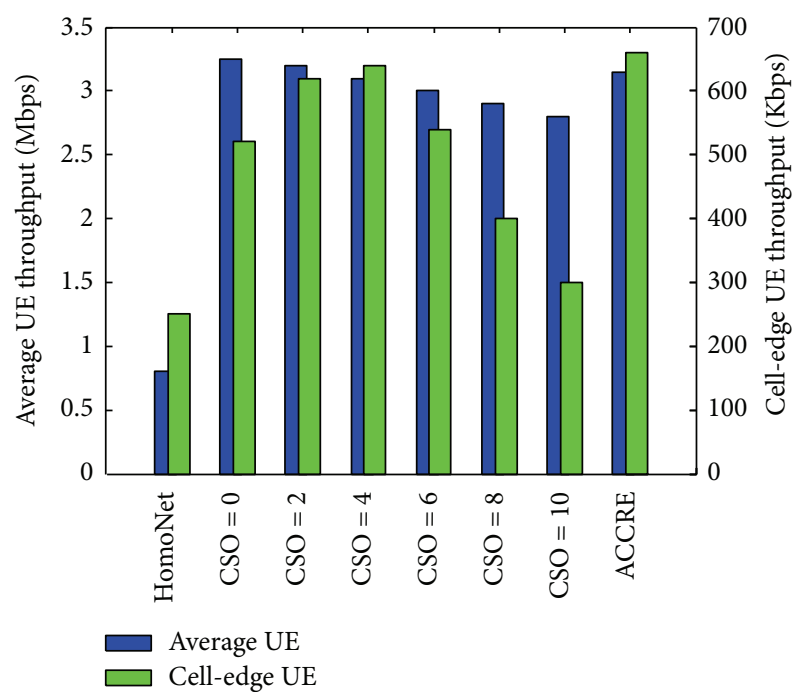

FIgURE 11: Throughput performance of the ACCRE algorithm [10].

\section{Comparison of the Adaptive Cell Selection Techniques}

Essentially, cell association schemes are intended for traffic load balancing as well as interference minimization and data rate maximization. An effective method for interference mitigation needs to be incorporated into the cell association algorithm to further enhance the performance of the offloaded UE, especially for the cell-edge UE. The RBUR algorithms in Gu et al. $[6,7]$ are traffic load-aware and channel-aware cell associations for load balancing and capacity maximization. The work in [7] considered the traffic loads in both MeNB and PeNB for adaptive bias setting, whereas the work in [6] used only the MeNB load condition. The study assumed that the PeNB is always resourced sufficiently, but this case is not always true, especially in a hotspot scenario. The ACCRE scheme in [10] considered only SINR as a criterion for the cell selection, and the SDACA algorithm in [9] used the combination of SINR and load condition to maximize the data rate of UE as a metric for cell association. The load condition and access probability derived from the scheduling technique employed can seriously affect the system throughput. For instance, an overloaded PeNB is resource limited; therefore, offloading even high SINR UE can further deteriorate the load situation in the PeNB. The Q-learningbased adaptive CRE algorithm in [8] is based on the amount of outage reduction to improve both cell-edge and average UE throughputs. Although the algorithm considered RB splitting as a measure for balancing the traffic load and interference minimization, there was no clear measurement conducted to maintain a balance between the metrics. Moreover, the number of outages broadcast from the MeNB through the backhaul may further add to the traffic load in the backhaul, and the signal may suffer delay or error from the amount of backhaul traffic.

The RBUR algorithm in Gu et al. [6, 7] also employed compensation for the data rate degradation due to interference by $\mathrm{RB}$ provisioning at the PeNB. There was no provision 
for the mitigation of the interference experienced by the celledge UE in the RBUR cell association algorithm. The Qlearning- [8] and SDACA- [9] based adaptive cell association schemes employed frequent domain ICIC to mitigate the effect of interference. The latter left a fraction of unused MeNB spectrum for the protection of PeNB UE and used all the spectrum for the PeNB. By contrast, the former used spectrum splitting between PeNB and MeNB, a strategy that is not optimal. A limitation of spectrum splitting is that it does not explain the procedure on how to arrive at a particular splitting ratio. Furthermore, spectrum splitting restricted the use of the spectrum to a fraction, thereby reducing the expected throughputs, especially the PeNB center UE and MeNB UE, which are not severely affected by the interference. The ACCRE algorithm in [10] used SINR as a metric for the cell association, and it impacted positively on the cell-edge UE throughput and enhanced the overall system performance.

The existing algorithms of adaptive cell association have failed to resolve the issue of imbalance between load balancing and rate maximization. The metrics were considered separately and not jointly optimizing the combination of the metrics as a new single metric which will result in a balanced system and better performance. Notably, the bias-based adaptive cell association prioritizes the MeNB through the maximum received signal strength-based cell selection and by assuming the PeNBs are always resource sufficient. This assumption is not always true because in hotspot scenarios, PeNBs are sometimes resource limited. Therefore, offloading more UE will further deteriorate the throughput performance. An unbiased cell association, for instance, the distance-based cell association, prioritizes the PeNBs and ensures load balancing when combined with loadaware or access-aware metrics in a hybrid manner. Optimal interference mitigation by resource muting or power control based on the ratio of the cell-edge UE and the MeNB UE needs to be incorporated into the hybrid algorithm to protect the offloaded cell-edge UE.

Nevertheless, adaptive cell selection techniques have been compared in terms of cell-edge UE throughput and average UE throughput performances. The network-acquired load estimation for cell association using the RBUR algorithm adaptively achieves a better throughput performance for the different UE distributions. As shown in Figure 12, the RBURbased cell load estimation proposed by Gu et al. [6] exhibits higher cell-edge throughput performance despite the use of the number of pieces of UE to estimate the cell traffic load condition. This was achieved because the RBUR algorithm has accurately estimated the load condition that enabled cell association. Also considering that the load estimate is acquired from the network side, thus it is immune to feedback errors. Unlike the first version of the RBUR algorithm, the RBUR extension proposed in Gu et al. [7] considered a typical CBR traffic service for a more accurate RBUR-based load estimation; this attribute is responsible for the performance improvement in terms of average UE throughput.

The Q-learning-based adaptive CRE algorithm in [8] is based on the amount of outage reduction for improving both cell-edge and average UE throughputs. Compared with

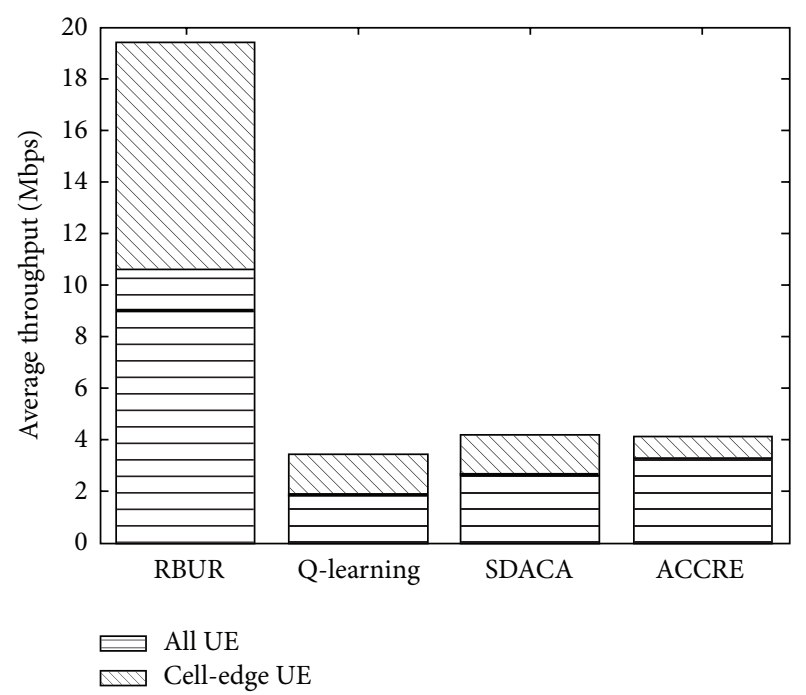

FIGURE 12: Comparison of average UE throughput.

the works of $\mathrm{Gu}$ et al. in $[6,7]$, the Q-learning inputs to the adaptive algorithm are acquired by $\mathrm{UE}$ on the basis of learning from previous experience. However, despite the learning ability of this algorithm and its distributed nature, some serious drawbacks, such as the long convergence time and feedback errors, exist unlike in $\mathrm{Gu}$ et al. works in $[6,7]$. Hence, the works of $\mathrm{Gu}$ et al. $[6,7]$ demonstrated improved performance in terms of cell-edge throughput and average UE throughput (Figure 12).

Unlike all the other cell selection techniques, the SDACA algorithm proposed in [9] is decentralized in nature, and hence the coordination among MeNBs is not necessary. Thus, it has better performance of cell-edge UE throughput and average UE throughput when compared to the Q-learning algorithm as shown in Figure 12. These attributes make the SDACA approach converge faster with better adaptation and control in accordance with the UE distribution. However, the approach is also associated with the problem of large signal overheads from feedback and ping-pong handover by multiple pieces of UE. This is because the effect of realistic propagation channel is not considered in the SDACA algorithm.

The centralized ACCRE algorithm was based on UE SINR [10]; as such, it adopted the ratio of the number of pieces of UE connected to the PeNBs and MeNB to represent the cell load metric similar to the algorithm proposed by $\mathrm{Gu}$ et al. [6]. However, despite the simplicity of this algorithm and its ability to solve the trade-off between cell-edge and average UE throughputs, it exhibit drawbacks such as feedback errors and inaccurate load estimation using a number of pieces of UE. Thus, the algorithm holds the least cell-edge UE throughput relative to all the other cell selection techniques explored (Figure 12). Nevertheless, the approach performs better in terms of average UE throughput when compared with the Qlearning and SDACA algorithms.

Table 1 depicts the comparative summary of the adaptive cell selection techniques, with emphasis on cell load representation, as input to the adaptive algorithms. The advantages 
TABLE 1: A comparative summary of the adaptive cell association schemes.

\begin{tabular}{|c|c|c|c|c|c|c|c|}
\hline $\begin{array}{l}\text { Proposed } \\
\text { scheme }\end{array}$ & $\begin{array}{l}\text { Algorithm } \\
\text { based on }\end{array}$ & $\begin{array}{c}\text { Cell load } \\
\text { metric } \\
\text { representation }\end{array}$ & $\begin{array}{l}\text { Inputs to cell } \\
\text { association } \\
\text { algorithm }\end{array}$ & $\begin{array}{l}\text { Cell-edge UE } \\
\text { throughput gain }\end{array}$ & $\begin{array}{l}\text { Average UE } \\
\text { throughput gain }\end{array}$ & Advantages & Drawbacks \\
\hline $\begin{array}{l}\text { Gu et al., } 2013 \\
{[6]}\end{array}$ & $\begin{array}{l}\text { Practical } \\
\text { adaptation } \\
\text { based on } \\
\text { cell-edge UE } \\
\text { capacity }\end{array}$ & $\begin{array}{c}\text { Number of } \\
\text { pieces of UE } \\
\text { based RBUR }\end{array}$ & $\begin{array}{l}\text { Network } \\
\text { acquired }\end{array}$ & $\begin{array}{c}\text { Nearly optimal } \\
\text { with } 70 \% \text { gain } \\
\text { over static at } \\
6 \mathrm{~dB}\end{array}$ & Not provided & $\begin{array}{l}\text { Simplicity and } \\
\text { immune to } \\
\text { feedback delays } \\
\text { and errors }\end{array}$ & $\begin{array}{l}\text { No criteria for } \\
\text { selecting the cell } \\
\text { load threshold }\end{array}$ \\
\hline $\begin{array}{l}\text { Gu et al., } 2014 \\
\text { [7] }\end{array}$ & $\begin{array}{l}\text { Practical } \\
\text { adaptation } \\
\text { based on } \\
\text { predicted } \\
\text { overall } \\
\text { capacity }\end{array}$ & $\begin{array}{c}\text { CBR traffic } \\
\text { based RBUR }\end{array}$ & $\begin{array}{l}\text { Network } \\
\text { acquired based } \\
\text { on system } \\
\text { capacity } \\
\text { prediction }\end{array}$ & Not provided & $\begin{array}{l}-9.4 \% \text { gain } \\
\text { compared to the } \\
\text { optimal }\end{array}$ & $\begin{array}{l}\text { Can achieve nearly } \\
\text { optimal } \\
\text { performance in all } \\
\text { cell load conditions }\end{array}$ & $\begin{array}{l}\text { The algorithm } \\
\text { updating } \\
\text { mechanism is } \\
\text { based on trial } \\
\text { and error }\end{array}$ \\
\hline $\begin{array}{l}\text { Kudo and } \\
\text { Ohtsuki, } 2013 \\
\text { [8] }\end{array}$ & $\begin{array}{l}\text { Q-learning } \\
\text { based on the } \\
\text { amount of } \\
\text { outage } \\
\text { reduction }\end{array}$ & $\begin{array}{l}\text { Set of ratio of } \\
\text { RBs and UE } \\
\text { distribution }\end{array}$ & $\begin{array}{l}\text { Distributed: } \\
\text { pieces of UE } \\
\text { learn their } \\
\text { optimal bias } \\
\text { values }\end{array}$ & $\begin{array}{c}61 \% \text { gain over } \\
\text { no learning } \\
\text { scheme at } 20 \% \\
\text { PRB }\end{array}$ & $\begin{array}{c}200 \% \text { gain } \\
\text { compared to } \\
\text { optimal at } 40 \% \\
\text { PRB }\end{array}$ & $\begin{array}{c}\text { Pieces of UE learn } \\
\text { its bias values from } \\
\text { past experience to } \\
\text { maximize network } \\
\text { throughput }\end{array}$ & $\begin{array}{c}\text { Long } \\
\text { convergence } \\
\text { time makes it } \\
\text { not suitable for } \\
\text { real systems. } \\
\text { Effect of UE } \\
\text { mobility not } \\
\text { considered. }\end{array}$ \\
\hline $\begin{array}{l}\text { Koizumi and } \\
\text { Higuchi, } 2013 \\
\text { [9] }\end{array}$ & $\begin{array}{c}\text { Simple } \\
\text { adaptation } \\
\text { based on } \\
\text { expected } \\
\text { minimum } \\
\text { average UE } \\
\text { throughput }\end{array}$ & $\begin{array}{l}\text { A combination } \\
\text { of MeNB index } \\
\text { and resource } \\
\text { index that } \\
\text { maximizes UE } \\
\text { throughput }\end{array}$ & $\begin{array}{l}\text { Decentralized: } \\
\text { no need for } \\
\text { coordination } \\
\text { among MeNBs }\end{array}$ & $\begin{array}{l}\text { 1.3-fold gain } \\
\text { compared to the } \\
\text { no ICIC case }\end{array}$ & $\begin{array}{c}1.3 \text {-fold } \\
\text { compared to the } \\
\text { no eICIC case }\end{array}$ & $\begin{array}{c}\text { Faster } \\
\text { convergence, } \\
\text { further enhanced } \\
\text { performance with } \\
\text { eICIC, and } \\
\text { adapting according } \\
\text { to the variation of } \\
\text { UE distribution }\end{array}$ & $\begin{array}{l}\text { Large overheads } \\
\text { due to feedback. } \\
\text { Ping-pong } \\
\text { handover } \\
\text { problem with } \\
\text { multiple pieces } \\
\text { of UE }\end{array}$ \\
\hline $\begin{array}{l}\text { Kikuchi and } \\
\text { Otsuka, } 2013 \\
{[10]}\end{array}$ & $\begin{array}{l}\text { Adaptive } \\
\text { control CRE } \\
\text { based on } \\
\text { SINR }\end{array}$ & $\begin{array}{l}\text { Ratio of the } \\
\text { number of } \\
\text { pieces of UE } \\
\text { connected to } \\
\text { PeNBs and } \\
\text { MeNBs }\end{array}$ & $\begin{array}{c}\text { Centralized } \\
\text { based on the } \\
\text { feedback from } \\
\text { UE }\end{array}$ & $\begin{array}{l}\text { Near-optimal } \\
\text { performance }\end{array}$ & $\begin{array}{c}\text { Slightly } \\
\text { above-optimal } \\
\text { performance: } \\
\text { 3.3 Mbps } \\
\text { compared to } \\
\text { optimal with } \\
\text { 3.2 Mbps }\end{array}$ & $\begin{array}{l}\text { Simple algorithm. } \\
\text { It has the ability to } \\
\text { solve the trade-off } \\
\text { between cell-edge } \\
\text { UE throughput } \\
\text { and the average UE } \\
\text { throughput }\end{array}$ & $\begin{array}{l}\text { Delay due to } \\
\text { feedback from } \\
\text { UE. Number of } \\
\text { pieces of UE } \\
\text { cannot } \\
\text { accurately } \\
\text { estimate the } \\
\text { cell's load } \\
\text { condition }\end{array}$ \\
\hline
\end{tabular}

and drawbacks of the techniques are also highlighted. The data show the importance of load estimation in traffic balancing and data rate improvement. For instance, the RBUR algorithm possesses the most accurate load estimation, which generates a high data rate. Further improvement to the RBUR algorithm using CBR traffic load produces an excellent throughput performance when compared with the traffic load estimation based on number of pieces of UE.

\section{Conclusion}

The HetNets deployment by LTE-Advanced is a technique employed by 3GPP to improve capacity when other methods evidently approach their Shannon capacity limits. However, the main challenge of overlaying PeNBs onto MeNBs in HetNets is the cell selection; this process results in a nonuniform traffic offload. The problem of cell selection in HetNets is attempted to be resolved using the CRE bias-based cell selection technique. However, given the dynamic nature of UE distribution and service demand, the desired goal of improved cell-edge and overall spectral efficiency cannot be achieved unless proper bias-based selection techniques are applied. Cell selection techniques using adaptive CRE bias algorithms to balance the traffic load for improved data rates were extensively reviewed in this work. The adaptive CRE bias-based cell selection with traffic load estimation offered a better solution for load balancing and improved cell splitting gain. The RBUR-based adaptive bias approach exhibited a better load balancing that results in high-throughput performance when compared with the other adaptive cell selection algorithms considered in this work. Furthermore, the RBUR ext algorithm using CBR performed excellently, and this result is due to the simplicity of the algorithm and the consideration of the data traffic while estimating load condition in the cell instead of using number of pieces of 
UE. This finding showed that traffic-load-based estimation improves the cell splitting gain when using adaptive cell selection in the downlink.

We suggest that future adaptive bias-based cell association be hybridized with the combination of the multiple metrics reviewed in this work and ensured a balance between the metrics to optimize system performance. Additionally, we recommend the development of hybrid non-bias-based cell association algorithm that prioritizes PeNBs. For instance, combined channel gain-aware and load-aware cell association can be jointly maximized with the optimal interference mitigation technique. This strategy not only would solve the problem of load balancing but also will result in an optimal joint uplink and downlink aware cell association with interference mitigation.

\section{Competing Interests}

The authors declare that there are no competing interests regarding the publication of this paper.

\section{References}

[1] 3GPP, "Feasibility study for further advancements for E-UTRA (LTE-Advanced)," Tech. Rep. 36.912 v10.0.0, 2011.

[2] S. Ahmadi, A Practical Systems Approach to Understanding 3GPP LTE Releases 10 and 11 Radio Access Technologies: LTEAdvanced, Academic Press, 2013.

[3] J. Acharya, L. Gao, and S. Gaur, Heterogeneous Networks in LTEAdvanced, 2014.

[4] Y. Xu, H. Xia, Z. Zeng, T. Zhang, and Y. Liu, "Performance of macro-pico heterogeneous networks based on LTE-advanced," in Proceedings of the 15th IEEE International Conference on Communication Technology (ICCT '13), pp. 298-303, IEEE, Guilin, China, November 2013.

[5] S. Sun, M. Kadoch, and T. Ran, "Adaptive SON and cognitive smart LPN for $5 \mathrm{G}$ heterogeneous networks," Mobile Networks and Applications, vol. 20, no. 6, pp. 745-755, 2015.

[6] X. Gu, W. Li, and L. Zhang, "Adaptive cell range control in heterogeneous network," in Proceedings of the International Conference on Wireless Communications and Signal Processing (WCSP '13), pp. 1-5, Hangzhou, China, October 2013.

[7] X. Gu, X. Deng, Q. Li, L. Zhang, and W. Li, "Capacity analysis and optimization in heterogeneous network with adaptive cell range control," International Journal of Antennas and Propagation, vol. 2014, Article ID 215803, 10 pages, 2014.

[8] T. Kudo and T. Ohtsuki, "Cell range expansion using distributed Q-learning in heterogeneous networks," EURASIP Journal on Wireless Communications and Networking, vol. 2013, article 61, 10 pages, 2013.

[9] T. Koizumi and K. Higuchi, "A simple decentralized cell association method for heterogeneous networks," IEICE Transactions on Communications, vol. E96-B, no. 6, pp. 1358-1366, 2013.

[10] K. Kikuchi and H. Otsuka, "Parameter optimization for adaptive control CRE in HetNet," in Proceedings of the IEEE 24th Annual International Symposium on Personal, Indoor, and Mobile Radio Communications (PIMRC '13), pp. 3334-3338, IEEE, London, UK, September 2013.

[11] S. Singh, H. S. Dhillon, and J. G. Andrews, "Offloading in heterogeneous networks: modeling, analysis, and design insights,"
IEEE Transactions on Wireless Communications, vol. 12, no. 5, pp. 2484-2497, 2013.

[12] S. Konishi, "Comprehensive analysis of heterogeneous networks with pico cells in LTE-advanced systems," IEICE Transactions on Communications, vol. 96, no. 6, pp. 1243-1255, 2013.

[13] J. Lim and D. Hong, "Mobility and handover management for heterogeneous networks in LTE-advanced," Wireless Personal Communications, vol. 72, no. 4, pp. 2901-2912, 2013.

[14] M. Salman, M. Abdulhasan, C. Ng, N. Noordin, A. Sali, and B. Mohd Ali, "Radio resource management for green 3gpp long term evolution cellular networks: review and trade-offs," IETE Technical Review, vol. 30, no. 3, pp. 257-269, 2013.

[15] C. Joe-Wong, S. Sen, T. Lan, and M. Chiang, "Multiresource allocation: fairness-efficiency tradeoffs in a unifying framework," IEEE/ACM Transactions on Networking, vol. 21, no. 6, pp. 1785-1798, 2013.

[16] J. G. Andrews, S. Singh, Q. Ye, X. Lin, and H. S. Dhillon, "An overview of load balancing in HetNets: old myths and open problems," IEEE Wireless Communications, vol. 21, no. 2, pp. 18 25, 2014.

[17] W. H. Chin, Z. Fan, and R. Haines, "Emerging technologies and research challenges for $5 \mathrm{G}$ wireless networks," IEEE Wireless Communications, vol. 21, no. 2, pp. 106-112, 2014.

[18] E. Dahlman, S. Parkvall, and J. Peisa, "5G wireless access," IEICE Transactions on Communications, vol. E98B, no. 8, pp. 14071414, 2015.

[19] N. Bhushan, J. Li, D. Malladi et al., "Network densification: the dominant theme for wireless evolution into 5G", IEEE Communications Magazine, vol. 52, no. 2, pp. 82-89, 2014.

[20] Y. Xu, H. Xia, Z. Zeng, T. Zhang, and Y. Liu, "Performance of macro-pico heterogeneous networks based on LTE-advanced," in Proceedings of the 15th IEEE International Conference on Communication Technology (ICCT '13), pp. 298-303, Guilin, China, November 2013.

[21] S. Fletcher and N. E. C. Telecom, "Cellular architecture and key technologies for $5 \mathrm{G}$ wireless communication networks," IEEE Communications Magazine, vol. 52, no. 2, pp. 122-130, 2014.

[22] S. Konishi, "Comprehensive analysis of heterogeneous networks with pico cells in LTE-advanced systems," IEICE Transactions on Communications, vol. E96-B, no. 6, pp. 1243-1255, 2013.

[23] Y. Li, X. Xu, J. Han, and W. Liu, "Coordinated inter-cell interference management for expanded region picocells in heterogeneous network," in Proceedings of the IEEE 78th Vehicular Technology Conference, pp. 1-5, IEEE, Las Vegas, Nev, USA, September 2013.

[24] S. Deb, P. Monogioudis, J. Miernik, and J. P. Seymour, "Algorithms for enhanced inter-cell interference coordination (eICIC) in LTE HetNets," IEEE/ACM Transactions on Networking, vol. 22, no. 1, pp. 137-150, 2014.

[25] M. A. Gadam, A. A. Maryam, N. K. Nordin, A. B. Sali, and F. Hisyam, "Decentralized time domain muting for interference mitigation in LTE-advanced heterogeneous networks," in Proceedings of the IEEE Conference on Sustainable Utilization and Development in Engineering and Technology (CSUDET '15), pp. 17-22, Selangor, Malaysia, October 2015.

[26] B. E. Priyanto, S. Kant, F. Rusek, S. Hu, J. Chen, and C. Wugengshi, "Robust UE receiver with interference cancellation in LTE advanced heterogeneous network," in Proceedings of the IEEE 78th Vehicular Technology Conference (VTC Fall '13), pp. 1-7, IEEE, Las Vegas, Nev, USA, September 2013. 
[27] A. Ghosh, N. Mangalvedhe, R. Ratasuk et al., "Heterogeneous cellular networks: from theory to practice," IEEE Communications Magazine, vol. 50, no. 6, pp. 54-64, 2012.

[28] J. Kim, D. Lee, and W. Sung, "Interference coordination of heterogeneous LTE systems using remote radio heads," EURASIP Journal on Advances in Signal Processing, vol. 2013, article 90, 8 pages, 2013.

[29] E. Hossain, M. Rasti, H. Tabassum, and A. Abdelnasser, "Evolution toward 5G multi-tier cellular wireless networks: an interference management perspective," IEEE Wireless Communications, vol. 21, no. 3, pp. 118-127, 2014.

[30] S.-S. Sun, W. Liao, and W.-T. Chen, "Traffic offloading with rate-based cell range expansion offsets in heterogeneous networks," in Proceedings of the IEEE Wireless Communications and Networking Conference (WCNC '14), pp. 2833-2838, Istanbul, Turkey, April 2014.

[31] Q. Ye, B. Rong, Y. Chen, M. Al-Shalash, C. Caramanis, and J. G. Andrews, "User association for load balancing in heterogeneous cellular networks," IEEE Transactions on Wireless Communications, vol. 12, no. 6, pp. 2706-2716, 2013.

[32] S. Singh and J. G. Andrews, "Joint resource partitioning and offloading in heterogeneous cellular networks," IEEE Transactions on Wireless Communications, vol. 13, no. 2, pp. 888-901, 2014.

[33] M. M. Ahamed and S. Faruque, "Path loss slope based cell selection and handover in heterogeneous networks," in Proceedings of the IEEE International Conference on Electro/Information Technology (EIT '15), pp. 499-504, Dekalb, Ill, USA, May 2015.

[34] X. Zhang and X. Zhou, LTE-Advanced Air Interface Technology, 2012.

[35] M. Khan and K. Han, "A Review of handover techniques in wireless Ad hoc networks based on IEEE 802.21 media independent handover standard," IETE Technical Review, vol. 31, no. 5, pp. 353-361, 2014.

[36] H. Shimodaira, G. K. Tran, K. Sakaguchi et al., "Optimization of picocell locations and its parameters in heterogeneous networks with hotspots," IEICE Transactions on Communications, vol. E96-B, no. 6, pp. 1338-1347, 2013.

[37] A. U. Ahmed, M. T. Islam, and M. Ismail, "A review on femtocell and its diverse interference mitigation techniques in heterogeneous network," Wireless Personal Communications, vol. 78, no. 1, pp. 85-106, 2014.

[38] M. H. M. Elsayed and A. Mohamed, "Distributed interference management using Q-Learning in cognitive femtocell networks: new USRP-based implementation," in Proceedings of the 7th International Conference on New Technologies, Mobility and Security (NTMS '15), pp. 1-5, Paris, France, July 2015.

[39] T. Kudo and T. Ohtsuki, "Cell selection using distributed Qlearning in heterogeneous networks," in Proceedings of the AsiaPacific Signal and Information Processing Association Annual Summit and Conference, pp. 1-6, IEEE, Kaohsiung, Taiwan, November 2013.

[40] K. Kikuchi and H. Otsuka, "Proposal of adaptive control CRE in heterogeneous networks," in Proceedings of the IEEE 23rd International Symposium on Personal, Indoor and Mobile Radio Communications (PIMRC '12), pp. 910-914, Sydney, Australia, September 2012. 


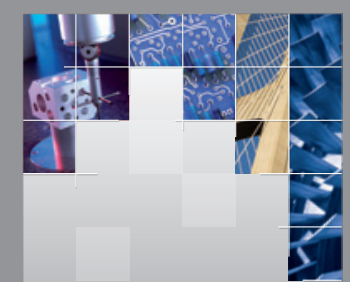

\section{Enfincering}
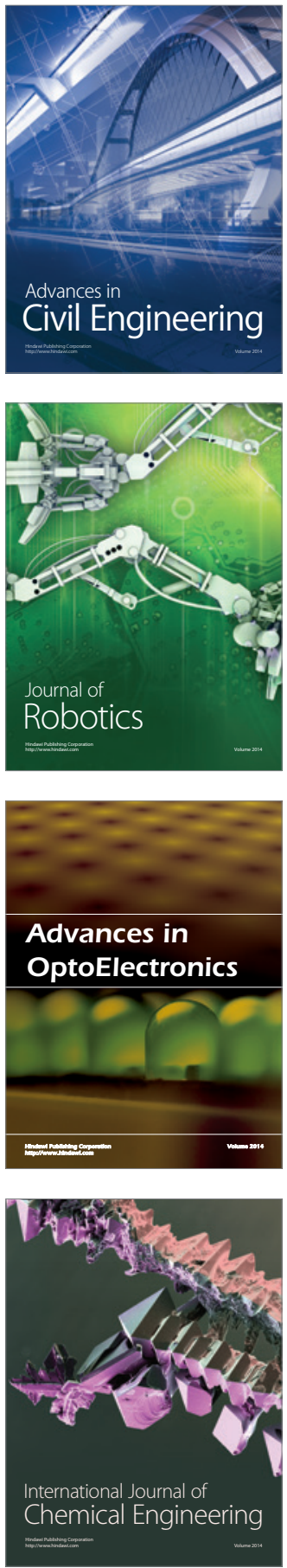

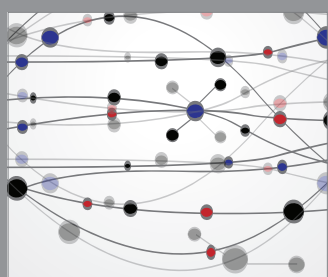

The Scientific World Journal

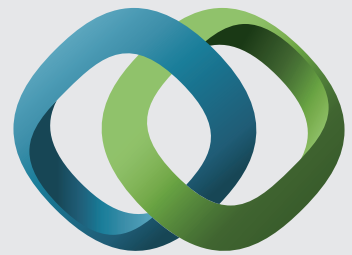

\section{Hindawi}

Submit your manuscripts at

http://www.hindawi.com
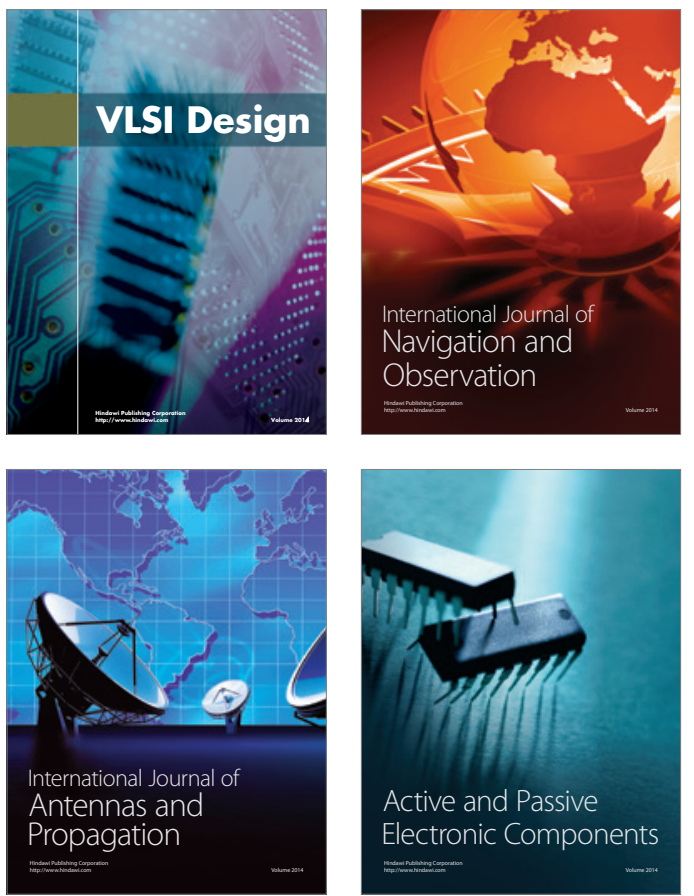
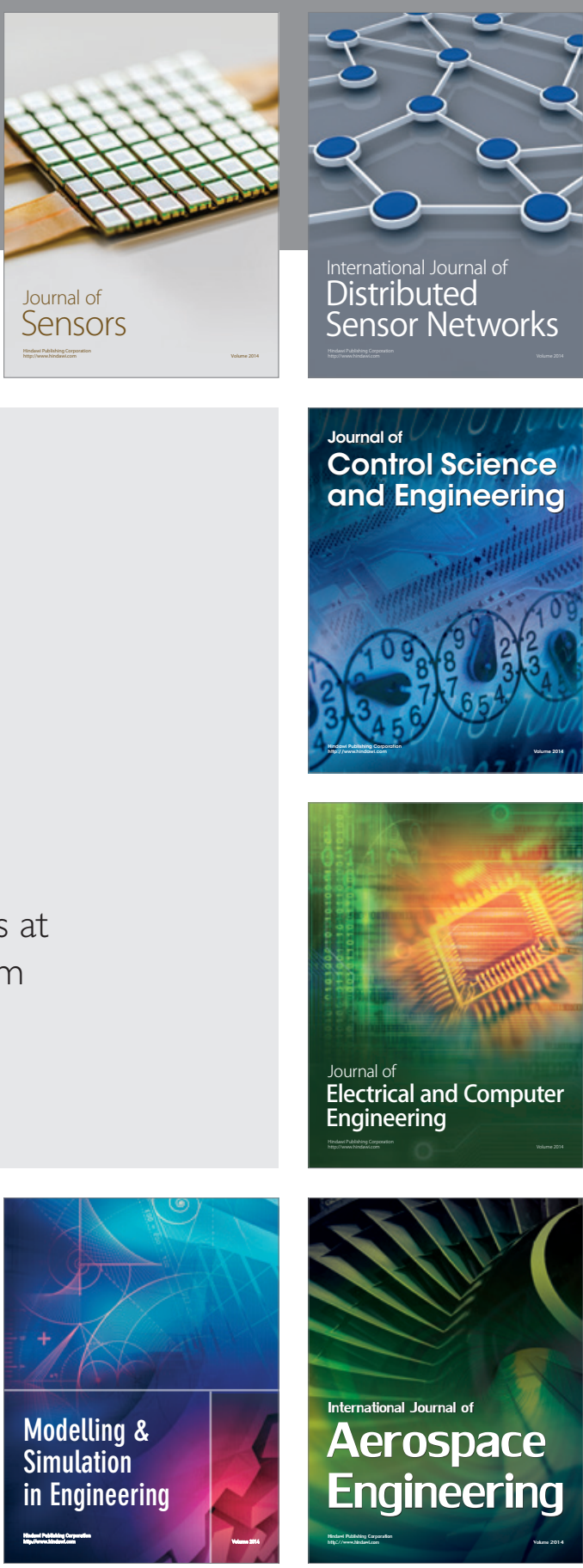

International Journal of

Distributed

Sensor Networks

Journal of

Control Science

and Engineering
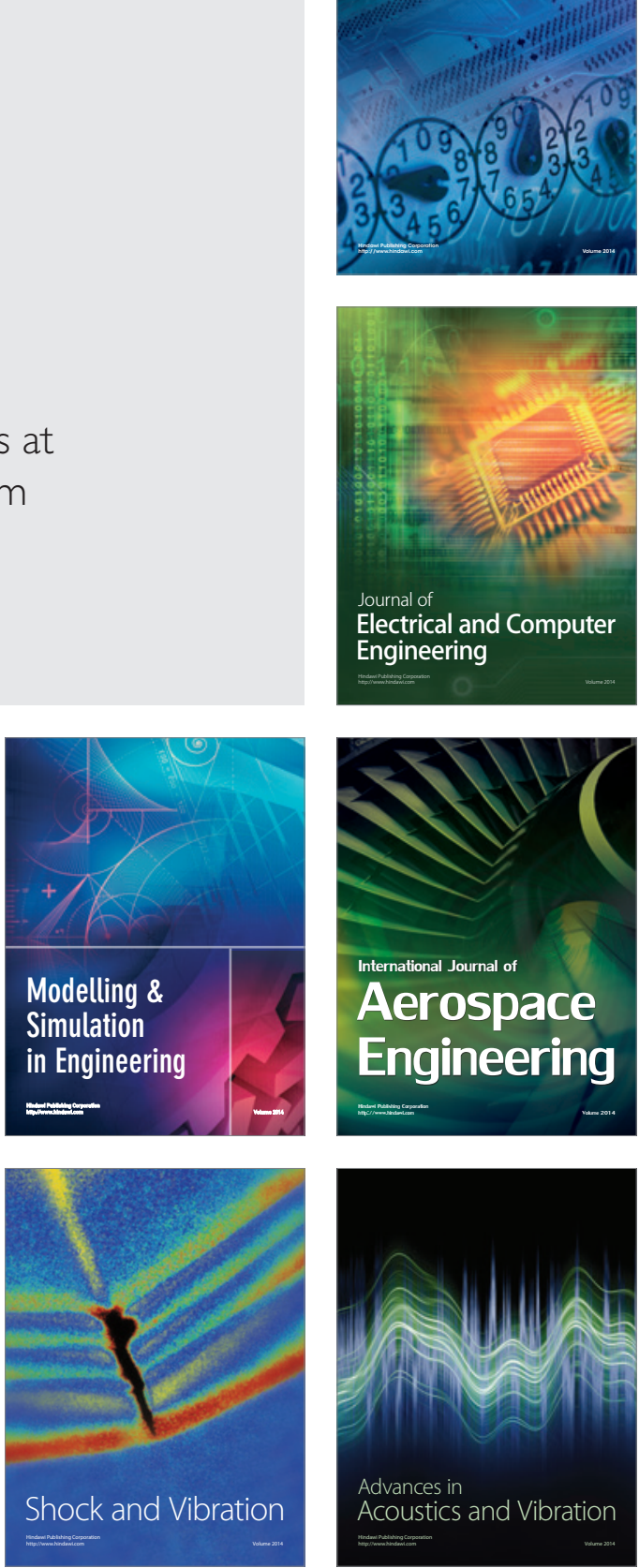